\title{
El repartimiento de Tenerife (1493-1569)
}

\author{
2 FRANCISCO BÁ EZ HERNÁNDEZ \\ La Laguna: Instituto de Estudios Canarios \\ 2016 | ISBN 978-84-697-8228-6 | 731 pp.
}

DOI: https://doi.org/10.22380/20274688.225I

E 1 repartimiento de Tenerife es un tema que ha interesado a los historiadores desde el nacimiento de la disciplina histórica a mediados del siglo XVIII. Ya el historiador ilustrado José de Viera y Clavijo intentó dar cuenta de sus principales rasgos en Noticias de la historia general de las Islas Canarias ${ }^{\mathrm{T}} \mathrm{y}$, desde entonces, el repartimiento se ha convertido en un tema de estudio que ha sido tratado por los principales historiadores del archipiélago canario. A mediados del siglo xx, Elías Serra y Leopoldo de la Rosa trataron de analizar el proceso, y a sus pioneros trabajos siguieron otros que abordaban el tema de forma parcial o colateral. Así, esta obra completa toda una serie de estudios sobre los repartimientos de Canarias, a cargo de Manuela Ronquillo y Eduardo Aznar Vallejo en el caso del repartimiento de Gran Canaria; Ana Viña Brito con respecto a la Palma; Manuel Lobo Cabrera en relación con las mercedes señoriales en tierras de Fuerteventura; además de los numerosos estudios comarcales referidos al repartimiento de Tenerife, realizados por Francisca Moreno Fuentes, Agustín Guimerá Rabina, Juan Ramón Núñez Pestano, Juan Manuel Bello León, Roberto González Zalacain y el propio Francisco Báez. En todos estos estudios

I Especialmente el capítulo xxx, “De los repartimientos de Tenerife y sus reformas”, en el que Viera analiza el repartimiento conforme a cuatro "principios de economía”: " $1 .{ }^{\circ}$ Distribuir las tierras de regadío por suertes pequeñas. $2 .^{\circ}$ Dar algunas de secano a centenares. $3 .^{\circ}$ Tener en más consideración a los conquistadores que a los simples pobladores, y a los de a caballo que a los soldados de infantería. $4 .^{\circ}$ No excluir de este beneficio a los naturales de las Islas” (274-275). 
sobresalía una conclusión general: el repartimiento carecía de regularidades, era el resultado de un ejercicio arbitrario que solo podía explicarse a partir de los intereses y la perspectiva individual de Alonso Fernández de Lugo, adelantado de la isla y encargado de la distribución de sus tierras y aguas.

En la obra que aquí se reseña, El repartimiento de Tenerife (I493-I569), resultado de la tesis doctoral de idéntico título defendida en la Universidad de La Laguna, en el 20I6, Francisco Báez ha ido más allá, para abordar por primera vez la cuestión desde una perspectiva globalizadora y explicar el repartimiento como un verdadero proceso de colonización, en el que, además de la arbitrariedad del repartidor, existía un proceso de repoblamiento del territorio en el que otros factores, hasta ahora poco considerados en la investigación (como las condiciones naturales y la debilidad de los recursos disponibles), desempeñaron un papel destacado en el éxito o fracaso de las concesiones de tierras (grandes o pequeñas), su poblamiento y su puesta en explotación. Esto se percibe en la novedad que implica rebasar, por primera vez, el marco cronológico de las datas (que concluyen en 1525) para centrar el objetivo en el proceso de formación de la propiedad territorial, la explotación de la tierra y la formación de los primeros núcleos de poblamiento. La cuestión sobresale ya en el propio título del trabajo que amplía la investigación hasta la primera mitad del reinado de Felipe II, cuando finaliza el procedimiento legal de reforma de los repartimientos.

Tratado el tema como un proceso de colonización, este enfoque trasciende la simple formalidad jurídica de la data para analizar el repartimiento como un complejo proceso de organización social del espacio. Para ello, el autor parte del análisis de un cuerpo ampliado de fuentes, que incluye una nueva transcripción, un cotejo y una reordenación de los libros de datas de repartimiento, así como la incorporación de datas originales conservadas en archivos de familia y el repartimiento realizado por Lope de Sosa, a las que aplica métodos propios de las humanidades digitales (transcripción digital y análisis sistemáticos de grandes volúmenes de datos), la antropología histórica (para analizar el proceso de antropización del medio) y los sistemas de información geográfica (ejemplificados en el minucioso rescate de toponimia que muestra en cada capítulo y el apéndice cartográfico de once mapas que recogen los cambios en el territorio introducidos a raíz del repartimiento y la colonización). Desde esta perspectiva interdisciplinar, el material documental disponible adquiere un nuevo sentido y puede ser interpretado como un método casi geográfico, en el que se trata de comprender en qué medida los nuevos pobladores asumieron la percepción del espacio propia de las comunidades aborígenes, pero también cuál fue el resultado de la simbiosis 
de esos conceptos con los modelos de organización del espacio (ganadero, agrícola, residencial, entre otros) propios de sus sociedades de origen, situadas en la Europa del Renacimiento.

La búsqueda de esa simbiosis entre la cultura del espacio de las sociedades aborígenes y de las europeas se plasma en el concepto de término, una voz castellana de vida efímera que solo pervivió como designación geográfica del territorio durante el siglo Xvi y que posteriormente pasó a designar a los términos de tierra y criazón, investigados por Juan Ramón Núñez Pestano ("Historia y paisaje”). El término no era el menceyato aborigen (demarcación de fijación dudosa), no era el alfoz municipal, ni la collación parroquial. De extensión más reducida (al menos en las cercanías de la ciudad capital) y mayor homogeneidad en cuanto a sus características geográficas, el término de Peñol o de Geneto se convierte en plural, en los términos de Adeje o los términos de Güímar cuando designa comarcas más amplias. Este es el concepto básico para agrupar e intentar explicar las datas y el proceso de ocupación del territorio, pues a partir de los términos se irán conformando la mayoría de los pueblos desde el siglo XVI. Por este motivo, Francisco Báez acomete en la exposición de los resultados una detallada descripción del proceso colonizador dividiendo la primera parte de la obra en cada una de las comarcas de la isla y sus términos, deparándonos con innumerables explicaciones hasta ahora desconocidas para la historiografía oficial, como es el caso de un intento prematuro y fracasado de colonización en las costas de Adeje (Santa Cruz de Tenerife) a comienzos del siglo xvi en torno al emplazamiento de la ermita de La Enramada, o la existencia de un corredor deforestado de tierra desde la época aborigen, en los altos de El Tanque y el Erjos, que comunicaba los pastos de Daute (al noroeste de la isla) con las bandas del suroeste de Tenerife.

Si bien el análisis del territorio a partir del concepto de término constituye el grueso de la obra, Francisco Báez acomete además un análisis más clásico, propio de un historiador de oficio, ofreciéndonos en la segunda parte del libro una exposición detallada del proceso del repartimiento, a partir del estudio de las formas jurídicas (datas y mercedes reales), el problema de la métrica de las concesiones, las formas de adquisición de la posesión y, sobre todo, una cronología precisa del proceso desde la incierta etapa inicial (I493-I500); la época de los repartimientos de aguas y tierras de regadío (I5OI-I505); el periodo convulso de la primera reforma del repartimiento (I506-I5Io); el flujo masivo de colonos y la época de los grandes repartimientos (I5II-I5I8), para terminar con los últimos años de Alonso Fernández de Lugo y la acción de su hijo, el segundo 
adelantado, adentrándose en la época de las mercedes de tierras otorgadas por la Corona y las usurpaciones (I536-I569). Esta cronología permite comprender el repartimiento de Tenerife como un proceso concentrado, básicamente, entre I5OI y I5I8, desligándolo en parte de la cronología del primer adelantado. Si por algo destaca el enfoque de Francisco Báez, es por señalar la clara diferencia existente entre el proceso de concesión de títulos de propiedad y la colonización propiamente dicha, que se retrasó más de un siglo para algunas comarcas de la isla. Así, el autor muestra cómo las tierras del sur de Tenerife, con la excepción del valle de Güímar y los ingenios de Adeje y Chasna, eran auténticos despoblados hasta la década de 1580, cuando comenzó la colonización de las zonas de Arico y Granadilla. En cuanto a la comarca de Isora, esta era considerada (incluso a comienzos del siglo XVII) un área semisalvaje, refugio de forajidos e insegura.

En definitiva, estamos ante una obra fundamental para comprender los primeros procesos de colonización europea en el espacio atlántico no peninsular y avanzar en posibles investigaciones comparadas con los anteriores repartimientos en la península ibérica y los posteriores de los espacios americanos.

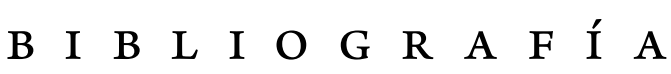

Báez Hernández, Francisco y Roberto González Zalacain. "Familia y estructura de la propiedad de la tierra en Tenerife a principios del siglo Xvi. El ejemplo de Taganana”. La torre: homenaje a Emilio Alfaro Hardisson, coordinado por Carlos Rodríguez Morales. La Laguna: Artemisa Ediciones, 2005, pp. 69-84.

Báez Hernández, Francisco. La Comarca de Tegueste (1497-1569). Un modelo de organización del espacio a raiz de la conquista. Santa Cruz de Tenerife: Ayuntamiento de Tegueste, 2006.

Bello León, Juan Manuel. "La participación de los extranjeros en los repartimientos canarios: introducción a un estudio". El Museo Canario, n. ${ }^{\circ}$ 53, 1998, pp. 187-214.

--.. "El reparto de tierras en Tenerife tras la conquista: el modelo del valle de la Orotava”. Historia. Instituciones. Documentos, n. ${ }^{\circ} \mathrm{I} 7, \mathrm{1} 990$, pp. I-30.

---. "Repoblación y repartimiento de Gran Canaria (I480-1525)”. Homenaje a Manuela Marrero, editado por Juan Manuel Bello León. La Laguna: Instituto de Estudios Canarios, I993, pp. I3I-I 45 . 
Guimerá Ravina, Agustín. “¿Canarias, ensayo de la colonización americana?: el repartimiento de la tierra en La Española”. América y la España del siglo XVI. Madrid: Servicio de Publicaciones Consejo Superior de Investigaciones Científicas, 1993, pp. 175-190.

--.. El repartimiento de Daute (Tenerife), I498-1529. Las Palmas de Gran Canaria: Cabildo de Gran Canaria, 1980.

Lobo Cabrera, Manuel. "Mercedes de tierras en Fuerteventura”. Anuario de Estudios Atlánticos, n. ${ }^{\circ}$ 59, 2013, pp. 85-119.

Moreno Fuentes, Francisca. "Repartimiento de vecinos de La Laguna en 1514 ”. Anuario de Estudios Atlánticos, n. ${ }^{\circ}$ 24, 1978, pp. 383-395.

Ronquillo Rubio, Manuela y Eduardo Aznar Vallejo, editores. Repartimientos de Gran Canaria. Vol. 6. Las Palmas de Gran Canaria: Museo Canario, 1998.

Núñez Pestano, Juan Ramón. “Campesinado, cambio agrario y usos comunales: la dehesa de La Laguna (Tenerife), I 498-1769". Historia Agraria: Revista de Agricultura e Historia Rural, n. ${ }^{\circ}$ 64, 2014 , pp. 13-4I.

---. "Historia y paisaje cultural: los partidos de ‘tierra y criazón’ en las cumbres del Oeste de Tenerife". Anuario de Estudios Atlánticos, n. ${ }^{\circ}$ 64, 2018 , pp. I-30.

--.. "El repartimiento de Tenerife y el origen de los montes concejiles". Historia de los montes de Tenerife. Capítulo i, tomo I. La Laguna: Universidad de La Laguna, 20 I , pp. 2 I-66.

Serra Ràfols, Elías y Leopoldo de la Rosa Olivera. Reformación del repartimiento de Tenerife en I506. Santa Cruz de Tenerife: Instituto de Estudios Canarios, 1953.

Viera y Clavijo, José de. Noticias de la historia general de las Islas Canarias. Volumen II. Santa Cruz de Tenerife: Idea, 2016.

Viña Brito, Ana. Conquista y repartimiento de la isla de La Palma. Santa Cruz de Tenerife: Búho Ediciones, 1997.

---. "La participación de la mujer en la repoblación de Canarias". Revista de Historia Canaria, n. ${ }^{\circ}$ 178, 1996, pp. 171-187. 